\title{
Correction to: Threshold Effect of Globalization on Democracy: the Role of Demography
}

\author{
Houda Haffoudhi ${ }^{1,2,3}$ (D) Rihab Bellakhal ${ }^{2,3,4}$ \\ Published online: 1 December 2020 \\ (C) Springer Science+Business Media, LLC, part of Springer Nature 2020
}

\section{Correction: J Knowl Econ (2020) https://doi.org/10.1007/s13132-020-00639-z}

The original version of this article unfortunately contained a mistake. Equation was incorrectly captured

Thus, this erratum is presented to fix this error.

$$
D_{i t}=\mu_{i}+\beta^{\prime} X_{i t}+\theta_{1} G_{i t} I\left(d_{i t} \leq \gamma\right)+\theta_{2} G_{i t} I\left(d_{i t}>\gamma\right)+\varepsilon_{i t}
$$

The original article has been corrected.

Publisher's Note Springer Nature remains neutral with regard to jurisdictional claims in published maps and institutional affiliations.

The online version of the original article can be found at https://doi.org/10.1007/s13132-020-00639-z

Houda Haffoudhi

haffoudhi.houda@gmail.com

1 FSEGN, Université de Carthage, Campus universitaire Mrezga, 8000 Nabeul, Tunisia

2 Tunis Business School, P.O. Box nº5, Bir El Kassaa, 2059 El Mourouj, Tunisia

3 MASE-ESSAIT, B.P 675, 6 Rue des Métiers, 1080 Tunis, Tunisia

4 University of Manouba, ESCT, Campus Universitaire Manouba, 2010 Manouba, Tunisia 